\title{
Comparison of latex and haemolysin tests for determination of anti-streptolysin O (ASO) antibodies
}

\author{
G D W CURTIS, WILMA A G KRAAK, R G MITCHELL \\ From the Bacteriology Department, John Radcliffe Hospital, Headington, Oxford
}

SUMMARY A latex agglutination test was compared with the micro-titration haemolysin inhibition method for the detection of anti-streptolysin O (ASO) antibodies in 428 serum samples. After slight modification of the latex method to produce maximal agglutination good agreement was shown between the results obtained by the two methods. The latex test had a sensitivity of $83.6 \%$, a specificity of $93.3 \%$, a predictive positive value of $86.5 \%$ and a predictive negative value of $91.6 \%$. It was convenient, required less labour than the haemolysin test, and permitted economic testing of small numbers of sera.

The long established method of quantifying anti-streptolysin O (ASO) antibodies by the ability of sera to inhibit the haemolytic effect of streptolysin $O$ on sheep erythrocytes is time consuming and expensive as the reduced streptolysin $O$ used in the test has a useful life of only six hours once reconstituted.' Because of these constraints most laboratories batch sera and set up tests only when sufficient sera have accumulated to justify the expense.

The use of latex agglutination tests avoids the need for erythrocyte suspensions but until recently streptolysin $\mathbf{O}$ was still required as a separate reagent for sensitisation. We report on a simple latex agglutination kit which provides particles pre-sensitised with streptolysin $O$ and compare the results with those of the haemolysin inhibition test.

\section{Material and methods}

All sera received in the laboratory for ASO titres from December 1986 to March 1988 were tested by both haemolysin and latex methods. The two tests were carried out independently on samples which had been stored at $4^{\circ} \mathrm{C}$ for up to one week or frozen at $-20^{\circ} \mathrm{C}$ for up to one year. A total of 428 samples was tested by both haemolysin and latex tests.

\section{HAEMOLYSIN TEST}

Reagents were from Wellcome Diagnostics, Dartford, England. The microtitration method recommended by the manufacturers was used except that three doubling

Accepted for publication 21 July 1988 dilution series were prepared starting at $1 / 25,1 / 30$, and $1 / 40$ extending to $1 / 1280$. The initial serum dilutions were inactivated by heating at $56^{\circ} \mathrm{C}$ for 30 minutes. Sheep cells were used to show haemolysis.

\section{LATEX TESTS}

The latex reagent (Rapi Tex ASL, Behring, Hounslow, England) consisted of an aqueous suspension of polystyrene latex particles sensitised with streptolysin O. The positive $(>50 \mathrm{IU} / \mathrm{ml})$ and negative $(<10 \mathrm{IU} /$ $\mathrm{ml}$ ) control sera provided with each kit were included in each test run together with two sera with haemolysin titres of $300 \mathrm{IU} / \mathrm{ml}$ and $600 \mathrm{IU} / \mathrm{ml}$ to monitor daily variations. The manufacturer's instructions were followed, with dilutions of sera made in physiological saline. For initial screening one volume of serum was added to five volumes of saline. Sera which gave a positive agglutination reaction at this dilution equivalent to $200 \mathrm{IU} / \mathrm{ml}$, were further tested at dilutions of $1 / 11,1 / 16,1 / 21,1 / 31$ and $1 / 41$, which approximated to $300,400,600,800,1200$, and 1600 IU $/ \mathrm{ml}$.

Duplicate series of dilutions were prepared from 31 sera and tested in parallel for latex agglutination after one of each pair was inactivated by heating at $56^{\circ} \mathrm{C}$ for 30 minutes. Subsequently sera were not routinely inactivated.

The instructions directed that one drop (about 40 $\mu$ ) of serum dilution and one drop of latex reagent were mixed on a slide with a stirring rod (not provided in the kit) and the slide rotated for two minutes at an unspecified speed.

In the preliminary stages the slides were rotated by hand. To test the effect of different rotation speeds 
Table 1 Results (IU/ml) of five sera tested by ASL at different rotation speeds

\begin{tabular}{ccccc}
\hline & Haemolysin & \multicolumn{4}{c}{ Rapi Tex ASL rotation speed (rpm) } \\
\cline { 3 - 5 } & test & 50 & 100 & 150 \\
\hline 1 & $<50$ & $<200$ & $<200$ & $<200$ \\
2 & 240 & $<200$ & 200 & 200 \\
3 & 400 & 300 & 300 & 400 \\
4 & 480 & 200 & 300 & 400 \\
5 & 640 & 400 & 600 & 600 \\
\hline
\end{tabular}

replicate tests on five sera of graded ASO titre by the haemolysin test were set up and rotated on a mechanical rotator at 50,100 , and $150 \mathrm{rpm}$ for two minutes. Attempts to run tests at $200 \mathrm{rpm}$ were abandoned due to the difficulty of keeping the slides in place on the rotator and the drops of reaction mixture discrete on the slides. A further 233 sera were tested in parallel at 100 and $150 \mathrm{rpm}$, and as a result of this comparison a speed of $150 \mathrm{rpm}$ was used for the remaining tests.

\section{Results}

Of the 31 sera tested by ASL before and after inactivation, 26 showed no change in titre. The titres of the other five sera showed a difference of one dilution step only between the inactivated and uninactivated dilution series.

Manual rotation of latex tests performed in duplicate by different workers showed considerable differences in titres. This was found to be due to variations in the speed of rotation (results not shown). Titres of five sera tested at three different rotation speeds are shown in table 1.

Thirty three of the 233 sera tested in parallel at 100 and $150 \mathrm{rpm}$ were positive at the screening dilution $(\geqslant 200 \mathrm{IU} / \mathrm{ml})$ and were titrated (table 2$)$. The paired $t$ test ( $32 \mathrm{df})$ showed that titres were significantly higher when tests were rotated at $150 \mathrm{rpm}(\mathrm{p}<0.02)$.

On one occasion when a new batch of latex reagent was used the control sera failed to react to the expected titre. This batch of reagent was replaced by the
Table 2 Correlation of latex ASO titres (IU/ml) of 33 sera tested in parallel at 100 and $150 \mathrm{rpm}$

\begin{tabular}{cllllll}
\hline & $\begin{array}{l}\text { No of sera with titres shown } \\
\text { after rotation at }\end{array}$ \\
\cline { 2 - 6 } & IU/ml & 200 & 300 & 400 & 600 \\
\hline No of sera with titres shown & 200 & 3 & 4 & 1 & \\
after rotation at 100 rpm & 300 & 4 & 5 & 9 & \\
& 400 & & & 3 & 3 \\
& 600 & & & 1 & \\
\hline
\end{tabular}

manufacturer and the tests repeated with a different batch. On all other occasions the control sera agglutinated the latex reagent to the expected titre but not beyond. There was slight variation in the strength of agglutination at the end point from day to day but this was not sufficient to change the reading itself.

Table 3 shows a comparison of titres obtained in the haemolysin and latex tests. Results were considered to agree if the latex titre was within \pm one dilution step of the haemolysin titre. There were $32(7 \cdot 5 \%)$ discrepant results of which 26 were sera showing lower titres with the latex test than with the haemolysin method. Of the two sera negative in the latex test and with a titre of 320 in the haemolysin test, one had been tested on an earlier occasion by haemolysin titration with an end point at $240 \mathrm{IU} / \mathrm{ml}$, the other was very icteric.

The sensitivity of the latex test, using a cut off point of $200 \mathrm{IU} / \mathrm{ml}$, was $83.6 \%$, specificity $93.3 \%$, with predictive value of a positive result $86.5 \%$ and a predictive value of a negative result $91.6 \%$.

\section{Discussion}

The apparent increase in titre in the latex method with increase in rotation speed is presumably due to more intimate mixing of serum and antigen coated latex particles promoting agglutination, and it emphasises the need for standardisation of the method. Despite this adoption of a fixed speed for the latex method it was disappointing that a comparison of the haemolysin and latex titres showed so many dis-

Table 3 Comparison of results* of 428 sera assayed by the ASO haemolysin and latex tests

\begin{tabular}{|c|c|c|c|c|c|c|c|c|}
\hline & & \multicolumn{7}{|c|}{ Latex test $(I U / \mathrm{ml})$} \\
\hline & & $<200$ & 200 & 300 & 400 & 600 & 800 & 1200 \\
\hline Haemolysin test (IU/ml) & $\begin{array}{r}<200 \\
200 \\
240 \\
320 \\
400 \\
480 \\
640 \\
800 \\
960\end{array}$ & $\begin{array}{r}263 \\
14 \\
8 \\
2\end{array}$ & $\begin{array}{r}18 \\
8 \\
25 \\
5 \\
3 \\
1\end{array}$ & $\begin{array}{r}2 \\
10 \\
9 \\
7 \\
4\end{array}$ & $\begin{array}{r}1 \\
1 \\
2 \\
8 \\
7 \\
10 \\
3\end{array}$ & $\begin{array}{l}1 \\
1 \\
8 \\
3 \\
1\end{array}$ & $\begin{array}{l}l \\
1 \\
1\end{array}$ & \\
\hline
\end{tabular}

Numbers of discrepant results are shown in italics. 
crepant results (table 3 ). Readings of both tests were subjective and therefore to some extent imprecise. In a similar comparison Martelli et al used a nephelometer to read the latex tests. ${ }^{2}$ They reported fewer discrepant results than were found in our study: $4.8 \%$ compared with $7 \cdot 5 \%$, and two thirds of their discrepant results involved higher titres with the latex test whereas four fifths of ours involved lower titres. As they used the same dilution series for both haemolysin and latex tests better overall agreement between the two is to be expected in their study. The bias towards higher titres with the latex test in their hands could be accounted for by increased sensitivity of the nephelometric reading method.

The manufacturer's claim of $80 \%$ agreement between titres in latex and haemolysin inhibition tests based on work by Bach $e t a^{3}$ with a different latex preparation was substantiated by our work with the present slide test. The sensitivity and predictive value of a negative result were lower in our series than the values reported by Boreland et al ${ }^{4}$ with a similar kit from a different manufacturer but their series was smaller than ours and contained a greater proportion of positive sera, $58 \%$ compared with $34 \%$ in our series. The difference in prevalence of positive sera in the two test populations affects the predictive value of the result. ${ }^{3}$ Applying the current latex test with its sensitivity of $83.6 \%$ and specificity of $93.3 \%$ to the sera of Boreland $e t$ al would produce a predictive value for a positive result of $93.9 \%$ and for a negative result of $80 \cdot 1 \%$.

Cost comparisons were difficult to make because some wastage of reagents was inevitable with the haemolysin test and the cost of the latex test depended on the number of sera titrated. Based on the testing of twelve sera a week, with three titrations in the latex test, the cost of labour and reagents for the haemolysin test was $£ 24$ and for the latex test $£ 9$. The latex test requires less than a quarter of the labour of the haemolysin test and the stability of the latex reagent allows small numbers of sera to be tested economically.

We consider that the advantages of lower cost for each test, simplicity, and convenience of the latex test outweigh the slightly higher sensitivity of the haemolysin test and make the determination of ASO titres practicable in even the smallest laboratories.

We thank Hoechst UK Limited for the gift of Rapi Tex ASL kits.

\section{References}

1 Todd EW. Antigenic streptococcal haemolysin. J Exp Med 1932; 55:267-80.

2 Martelli P, Crovatto M, Toffulutti M, Grattoni E, Santini G. Valutazione comparativa di tre tests per la determinazione del titolo antistreptolisinico. Giorn Batt Virol Immun 1985; LXXVIII:34-42.

3 Bach GL, Cadotte R, Wiatr RA, Bhorade M, Anderson TO. Latex antistreptolysin $\mathrm{O}$ test as a tube dilution procedure. Am J Clin Pathol 1972;57:209-11.

4 Boreland PC, Thompson EA, Fenning G. Evaluation of a latex screening test for the detection of antistreptolysin $\mathrm{O}$ antibodies. Serodiagnosis and Immunotherapy 1987;1:113-6.

5 Vecchio TJ. Predictive value of a single diagnostic test in unselected populations. N Engl J Med 1966;274:1171-3.

Requests for reprints to: Mr G D W Curtis, Bacteriology Department, Level 7, John Radcliffe Hospital, Headington, Oxford OX9 3DU, England. 